\title{
Assessment of the progressive nature of cell damage in the pilocarpine model of epilepsy
}

L. Covolan and L.E. M ello
Departamento de Fisiologia, Universidade Federal de São Paulo, São Paulo, SP, Brasil

\section{Correspondence}

\section{L.E. Mello}

Departamento de Fisiologia

UNIFESP

Rua Botucatu, 862

04023-062 São Paulo, SP

Brasil

Fax: +55-11-5579-2033

E-mail: lemello@ecb.epm.br

Research supported by FAPESPCEPID, Institutos do Milênio, CN Pq, and PRONEX. L. Covolan was the recipient of a FAPESP fellowship (No. 95/0657-0).

Received September 23, 2005 Accepted April 24, 2006

\section{Abstract}

Pilocarpine-induced $(320 \mathrm{mg} / \mathrm{kg}$, ip) status epilepticus (SE) in adult (2-3 months) male Wistar rats results in extensive neuronal damage in limbic structures. Here we investigated whether the induction of a second $\mathrm{SE}(\mathrm{N}=6)$ would generate damage and cell loss similar to that seen after a first $\mathrm{SE}(\mathrm{N}=9)$. Counts of silver-stained (indicative of cell damage) cells, using the Gallyas argyrophil III method, revealed a markedly lower neuronal injury in animals submitted to re-induction of SE compared to rats exposed to a single episode of pilocarpineinduced SE. This effect could be explained as follows: 1) the first SE removes the vulnerable cells, leaving behind resistant cells that are not affected by the second SE; 2) the first SE confers increased resistance to the remaining cells, analogous to the process of ischemic tolerance. Counting of Nissl-stained cells was performed to differentiate between these alternative mechanisms. Our data indicate that different neuronal populations react differently to SE induction. For some brain areas most, if not all, of the vulnerable cells are lost after an initial insult leaving only relatively resistant cells and little space for further damage or cell loss. For some other brain areas, in contrast, our data support the hypothesis that surviving cells might be modified by the initial insult which would confer a sort of excitotoxic tolerance. As a consequence of both mechanisms, subsequent insults after an initial insult result in very little damage regardless of their intensity.
Key words

- Cell injury

- Status epilepticus

- Epilepsy

- Pilocarpine

- Spontaneous seizures

\section{Introduction}

Limbic seizures induced by systemic injections of pilocarpine provide a valuable animal model of temporal lobe epilepsy (TLE). Following the acute period of severe continuous epileptic activity (status epilepticus, SE), animals enter a latent period lasting a few weeks, during which no overt seizures are observed. This period is followed by a permanent chronic period in which behav- ioral spontaneous recurrent seizures (SRS) take place (1-3). It has been demonstrated that SE itself is critical for epileptogenesis in this model of TLE (4). However, the potential contribution of cell damage - and not only cell loss - to the epileptogenic process in experimental models and in human epilepsy is not yet clear. The debate about whether neuronal injury or even neuronal loss in TLE is the cause or consequence of seizures has been the subject of a number of 
studies in both human patients and animal models (5-7). All of the above studies support the view that SRS tends to produce only minor damage and it has been suggested that a history of previous seizure might confer resistance to further damage caused by subsequent seizures (8-11). This phenomenon has been proposed as an 'experience-induced' alteration in the mechanisms leading to cell death. Alternatively, it could be hypothesized that the initial insult results in the loss of most vulnerable cells, thus leaving relatively fewer cells to be damaged by subsequent lesional events.

The argyrophil III silver staining procedure is a useful and very reliable method for detecting the early histopathological state and localization of neurons after various brain insults, allowing the detection of even very few damaged cells in contrast to a light yellow neuropil (12-14). Here we addressed the issue of the effect of prior cell damage and cell loss on subsequent similar events in epileptic tissue by counting both argyrophil III- and Nissl-stained sections by assessing: 1) the effects of a second SE regarding cell injury in chronic epileptic animals, and 2) the influence of single spontaneous seizures
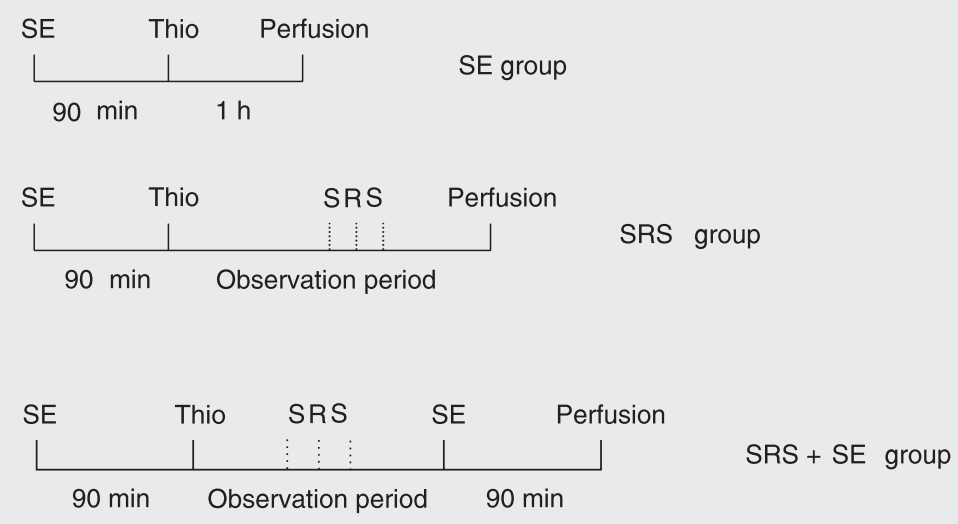

Figure 1. Schematic representation of the protocol used for the three experimental groups. Status epilepticus (SE) was induced in rats which were perfused $2.5 \mathrm{~h}$ later (SE group), or after a single or a cluster of stage IV-V spontaneous recurrent seizures (SRS group), or after a second bout of SE (SRS + SE group). All groups were handled and observed together over the same period of time. The observation period refers to 1-15 months for the SRS group and 6-7 months for the SRS + SE group. Thio = sodium thiopental. on cell damage in long-lasting epilepsy (animals sacrificed from 1 to 15 months after SE induction).

\section{Material and Methods}

\section{Animal treatment}

Adult male Wistar rats (150-250 g) were housed in groups of 6 on a standard lightdark cycle with rat chow pellets and tap water continuously available. The experiments were performed under institutional approval (Animal Research Ethics Committee of UNIFESP) and all ethical requirements were respected. In the 36 rats included in this study, seizures were induced by systemic injections of pilocarpine hydrochloride (320 mg/kg, ip, Merck, São Paulo, SP, Brazil) preceded by scopolamine methyl bromide $(1 \mathrm{mg} / \mathrm{kg}$, ip; Sigma, St. Louis, MO, USA) injected $30 \mathrm{~min}$ before to reduce the peripheral effects of pilocarpine. Approximately $30 \mathrm{~min}$ after pilocarpine injection, most of the animals had developed SE. Sodium thiopental $(25 \mathrm{mg} / \mathrm{kg}$, ip) was injected 90 min after SE onset to diminish the otherwise high mortality rates associated with tonic seizures. After SE, animals were behaviorally observed for approximately $4 \mathrm{~h} /$ day, 5 days/week for the occurrence of SRS, similar to Racine's kindled stages III (bilateral forelimb clonus), IV (stage III and rearing), and V (stage IV and loss of postural tone, i.e., rearing and falling). A schematic representation of the three experimental groups is shown in Figure 1.

\section{Acute animals perfused after SE (SE group)}

Nine animals were subjected only to a single episode of SE by means of pilocarpine as described above and were perfused $2.5 \mathrm{~h}$ after SE onset (for all animals, see perfusion procedures below). These previously naive animals, age-matched to the animals from the SRS + SE group, were used as controls. 


\section{Chronic animals perfused after SE re-induction (SRS + SE group)}

In a group of 6 chronically epileptic rats (all of which had had SE), a second bout of SE was re-induced at 6-7 months after the primary SE induction. For this procedure, these animals received the same dose and sequence of drugs as the SE group (see the group above). All animals were perfused about $2.5 \mathrm{~h}$ after SE onset.

\section{Chronic animals perfused after spontaneous recurrent seizures (SRS group)}

A few hours after the occurrence of either a single stage IV or $\mathrm{V}$ spontaneous seizure or after a cluster of shortly spaced SRS at 1 to 15 months after SE induction, animals were perfused and processed for histology $(\mathrm{N}=21)$. All perfusion procedures took place from 2 to $3 \mathrm{~h}$ after the last SRS in order to ensure that all possible injured cells would be stained.

\section{Silver staining procedure}

Animals were deeply anesthetized and perfused through the left ventricle according to the procedure described by Gallyas and colleagues (15-17). For all animals, the perfusion and silver staining procedures were similar to those described earlier (13). Briefly, under sodium thiopental anesthesia $(50 \mathrm{mg} /$ $\mathrm{kg}$ ), animals were transcardially perfused with buffered saline and cacodylate-buffered solution containing $2 \%$ paraformaldehyde and $2.5 \%$ glutaraldehyde. Brains were left in the skull for at least $24 \mathrm{~h}$ and postfixed in the same fixative for 1 week at room temperature. After cryoprotection and sectioning, one in every four coronal brain sections $(64-\mu \mathrm{m}$ thick) from all animals was dehydrated and esterified in 1-propanol containing $1.2 \%$ sulfuric acid and $2 \%$ distilled water. The sections were then rehydrated, washed, and treated with $3 \%$ acetic acid before immersion into a silicotungstate physical developer. Finally, the sections were mounted and coverslipped with Canada balsam. Adjacent sections were submitted to Nissl staining.

\section{Cell counting and statistical analysis}

The counting of stained cells was performed in six coronal sections at approximately 1 -mm intervals: $0.00,-1.08,-2.00$, $-3.25,-4.45$, and $-5.65 \mathrm{~mm}$ caudal from the bregma (18). Counts of neurons with profiles $>7 \mu \mathrm{m}$ having an identifiable nucleolus were made at $400 \mathrm{X}$ magnification with a BX50 Olympus microscope (Melville, NY, USA) coupled to a MacIntosh-based image analysis system (Cupertino, CA, USA) and Neurozoom software (La Jolla, CA, USA). It should be emphasized that Nissl-stained neuronal counting is a relative estimate and not an absolute calculation of the number of neurons. The data presented in Table 1 are values obtained from silver-stained cell counts for the SE group and are reported as means \pm SEM, except for a single animal, which markedly differed from its peers and is thus presented apart. Differences in mean values were determined by one-way analysis of variance (ANOVA) followed by the Student-Newman-Keuls post hoc test $(\mathrm{P} \leq$ $0.05)$. On the other hand, the small number of injured cells observed in many animals after SRS or after SE re-induction (Tables 2 and 3) does not permit us to report them as a mean value per group. Only those silverimpregnated cells for which the whole soma and proximal dendrites could be seen were counted. Animals in which no silver-stained cell was detected are not shown in the tables. Since even small diameter stainless electrodes would have produced silver-impregnated cells (see Figure 1A from Ref. 19), and that we could not keep these electrodes implanted for such a long time in some animals, we did not perform electroencephalographic recordings in any of these animals. 
Figure 2. Bright field photomicrographs of argyrophilic cells in piriform (left panels) and somatosensory (right panels) cortical areas in three experimental situations: acute status epilepticus (SE; A and B), chronic (C and $D$ ) and $S E$ re-induction ( $E$ and $F$ ). $A$, high density of silver-stained cells with their processes located mainly in piriform cortex layers II and III. C, an isolated horizontaloriented cell in layer III (white arrow) and atrophy of layer II. E, glial scarring in piriform cortex layer II (black arrows) possibly due to the first SE. Note in $E$ the absence of silver-stained cells, which would indicate further damage due to the second SE. In B, high number of silver-stained cells in layers III and IV (acute SE) should be compared to the absence of injury in $D$ and $F$ (animals from SRS or SRS + SE groups, respectively). Scale bar: $120 \mu \mathrm{m}$.
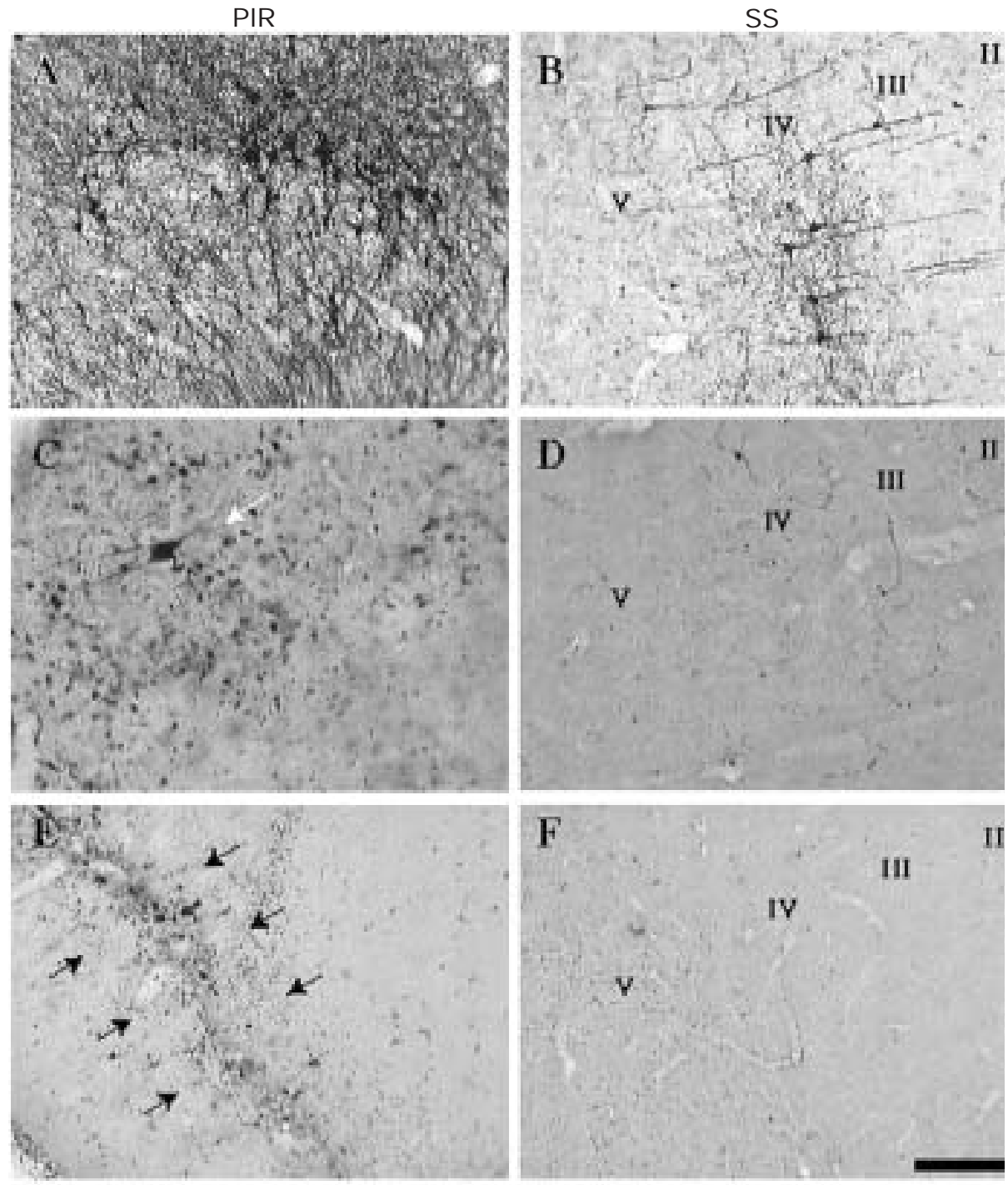

Table 1. Mean number of silver-stained cells at selected septotemporal levels in animals perfused $2.5 \mathrm{~h}$ after pilocarpine-induced status epilepticus.

\begin{tabular}{lcr}
\hline & \multicolumn{2}{c}{ Silver-stained cells (mean \pm SEM) } \\
\cline { 2 - 3 } & $\mathrm{N}=8$ & $\mathrm{~N}=1$ \\
\hline Somatosensory area & $4907.1 \pm 1404.1$ & 578 \\
Perirhinal area & $843.0 \pm 170.4$ & 167 \\
Piriform cortex & $1033.1 \pm 269$ & 109 \\
Claustrum & $662.5 \pm 137.7$ & 48 \\
CA1 stratum oriens & $90.8 \pm 21.7$ & 32 \\
Hilus & $384.3 \pm 20.1$ & 25 \\
Ventromedial nucleus of the hypothalamus & $88.6 \pm 23.2$ & 1 \\
Medial geniculate complex & $63.0 \pm 13.9$ & 30 \\
\hline
\end{tabular}

One animal is reported separately from the others given its markedly different profile of cell damage. Animals without silver-stained cells in these structures are not shown in this table. 
Thus, both SE and SRS were only monitored behaviorally.

\section{Results}

Behavioral features of pilocarpine-induced seizures during the acute period were similar to those previously reported (20). These progressed to SE approximately $40 \mathrm{~min}$ after pilocarpine injection. The seizure frequency among animals during the sampled period varied from animal to animal, with a mean of $1.42 \pm 0.23$ recorded seizures per week per animal. There were no clear-cut differences in the behavioral characteristics of SRS among animals relative to their short- or long-term follow-up. All animals submitted to the second injection of pilocarpine (SRS + SE group) immediately displayed body tremor progressing to SE in less than $5 \mathrm{~min}$. No SRS was observed in animals injected with pilocarpine that did not develop SE. The second SE was indistinguishable from the first SE regarding phenotype and severity. The anticonvulsant treatment was administered after $90 \mathrm{~min}$ of onset in both cases.

\section{Cell injury immediately after a single SE}

Silver-impregnated cells were abundant throughout all brain sections analyzed. Figure $2 \mathrm{~A}$ and $\mathrm{B}$ demonstrate the high fre- quency of silver-stained cells in the piriform and somatosensory cortical areas of one such animal perfused $2.5 \mathrm{~h}$ after SE onset. The nine rats perfused after a single SE episode were uniform regarding the pattern and extent of cell damage, with the exception of one animal which displayed a rather small number of silver-stained cells. For this animal, the number of silver-stained cells was reported separately from the other 8 to allow a better assessment of the data (see Table 1). Table 1 illustrates the mean frequency of silver-stained cells for selected brain structures. Control animals, which did not develop SE, did not have any silver-stained cell in any of the sections analyzed (and thus are not illustrated here).

\section{Cell injury in pilocarpine-chronic animals (months after SE)}

No single dark cell was encountered across the entire forebrain of the animals perfused between 25 and 40 days after SE (N $=6$ ), but other signals of injury such as atrophy and glial scar were seen, suggestive of past neurodegenerative processes.

In all of the remaining 15 animals from this group, perfused from 2 to 15 months after SE induction, the number of silverstained cells was always very low after SRS (Table 2), irrespective of when the animals

\begin{tabular}{|c|c|c|c|c|c|c|c|c|c|c|}
\hline Animal No. & Duration of epilepsy & SRS & BST & PIR & CA3 & CA3 so & CA1 so & VTA & CLA & $\mathrm{H}$ \\
\hline 28 & 60 days & 3 & 18 & - & - & - & - & - & 1 & - \\
\hline 29 & 65 days & 5 & - & 1 & - & - & 1 & - & - & - \\
\hline 30 & 66 days & 1 & - & - & 7 & 7 & 1 & - & - & - \\
\hline 15 & 10 months & 65 & - & 2 & - & - & - & - & - & 1 \\
\hline 16 & 15 months & 157 & - & - & - & - & - & 37 & - & - \\
\hline
\end{tabular}

Animals are identified by number. Duration of the epilepsy history is reported in days or months. The total number of recorded spontaneous recurrent seizures (SRS) is also reported. BST $=$ bed of the nucleus stria terminalis; $\mathrm{PIR}=$ piriform cortex; $\mathrm{CA} 3=$ hippocampal $\mathrm{CA} 3$ field, pyramidal cells; $\mathrm{CA} 3$ so $=$ hippocampal CA3 field, stratum oriens; CA1 so = hippocampal CA1 field, stratum oriens; VTA = ventral temporal areas; CLA = claustrum; $H$ = hilus. "-" = absence of silver-stained cells. Animals without silver-stained cells in these structures are not shown in this table. 
had been perfused. The brain areas containing stained neurons varied dramatically from one animal to another, but for a given structure, these cells generally showed a similar localization. In the hippocampus, almost none of the few injured cells were located in the principal cell layers and more neurons were seen in the CA1-CA3 oriens and alveus strata (relative to the density of cells in these areas), followed by dentate gyrus and CA1 stratum radiatum. The suprapyramidal dentate granule cell layer of the animal perfused 15 months after SE was totally atrophic. Other affected areas were nucleus accumbens, some of the amygdaloid nuclei, the ventral temporal cortex, and the perirhinal, piriform (layers II-III; see Figure 2C) and entorhinal cortices. Four animals from this group did not display any stained neuron in the predefined areas or levels. In any event, dark cells in these 4 animals were present in the hilus, entorhinal cortex, basomedial and lateral amygdala nuclei, claustrum and nonpyramidal CA1 cells.

\section{Silver-stained cells after SE re-induction in chronic animals (SRS + SE group)}

The distribution of silver-stained neurons in this group was similar to that observed in the previous groups. These neu-

\begin{tabular}{|c|c|c|c|c|c|c|c|c|}
\hline Animal No. & SS & PERI & PIR & CLA & CAl so & $\mathrm{H}$ & VMH & MGC \\
\hline 23 & 1 & - & - & - & 21 & 4 & 6 & 37 \\
\hline 33 & 37 & 4 & 7 & - & 1 & 4 & 6 & - \\
\hline 54 & - & 2 & 1 & 16 & - & - & 6 & - \\
\hline 55 & 1299 & 184 & 7 & 128 & 4 & 139 & 35 & 18 \\
\hline 56 & - & - & 3 & 1 & - & - & - & 2 \\
\hline
\end{tabular}

Animals are identified by number. Animals without silver-stained cells in these structures are not shown in this table. SS = somatosensory area; PERI = perirhinal area; $\mathrm{PIR}=$ piriform cortex; $\mathrm{CLA}=$ claustrum; $\mathrm{CA} 1$ so = hippocampal CA1 field, stratum oriens; $\mathrm{H}=$ hilus; $\mathrm{VMH}=$ ventromedial nucleus hypothalamus; $\mathrm{MGC}=$ medial geniculate complex; "-" = absence of silver-stained cells. rons were in piriform cortex, ventromedial nucleus hypothalamus, hippocampal hilus and CA1 stratum oriens, medial hypothalamic area, claustrum, dorsal and ventral parts of the medial geniculate complex, and somatosensory and perirhinal cortices (Figure $2 \mathrm{E}$ and $\mathrm{F}$, and Table 3). One animal with no silver-stained neurons in the listed brain areas also did not show any silver-stained neuron anywhere else in the brain and thus was not included in Table 3. All animals sacrificed after SE re-induction displayed extensive gliosis and atrophy in thalamic and amygdaloid nuclei, lateral septum, substantia nigra - reticular part, as well as auditive, visual, somatosensory, piriform, and entorhinal cortices.

\section{Cell density measurements}

The number of silver-stained and Nisslstained cells for the same brain structures and areas from the 3 groups (SE, SRS and $\mathrm{SRS}+\mathrm{SE}$ ) was counted to evaluate whether the reduced number of silver-stained neurons in the SRS + SE group when compared to the SE group was a result of the lower number of remaining neurons to be damaged in the second bout of SE (Figure 3). The Nissl-stained cell density was reduced for all counted areas, with cell density being lower in the SRS and SRS + SE groups. A different picture was encountered for the dentate granule cell layer given that, although this group was highly vulnerable to the first SE, an increase in the number of Nissl-stained cells was found for the SRS + SE group.

\section{Discussion}

The major findings of this study were that a second SE produces much less damage compared to the first SE both in terms of absolute cell counts and relative to the number of available cells; each SRS always damaged neurons, even though very few of them. Our current and previous (19) results of a 
very low number of silver-stained cells following SRS are in agreement with human clinical data showing that repeated temporal lobe seizures also contribute to neuronal loss (especially in the hippocampus), but only after many years of epilepsy and in specific brain areas (for a review, see Ref. 21). Thus, the current findings reinforce the similarities found between the pilocarpine model and human temporal lobe epilepsy.

The argyrophil III method adequately fits the purpose of this study due to its high reliability and sensitivity for detecting neuronal cells undergoing pathological processes early after a brain insult (12-14,22) even when these cells are very scarce. Indeed, it was suggested that this technique character- izes a reversible pathological phenomenon, not necessarily associated with immediate cell death (12). In this case, even if these silver-stained cells are not necessarily dying, they are subject to long-lasting cytoskeletal changes, which might bear relevance to the generation of further SRS. Indeed, if restricted but measurable numbers of interneurons are always injured after each single SRS, the cumulative effect of such damage could contribute in part to the recurrence of additional seizures. However, silver-impregnated cells might also include more vulnerable neurons that might be permanently impaired by a seizure. The specificity of the argyrophilic III staining is supported by the fact that dentate granule cells, which do not

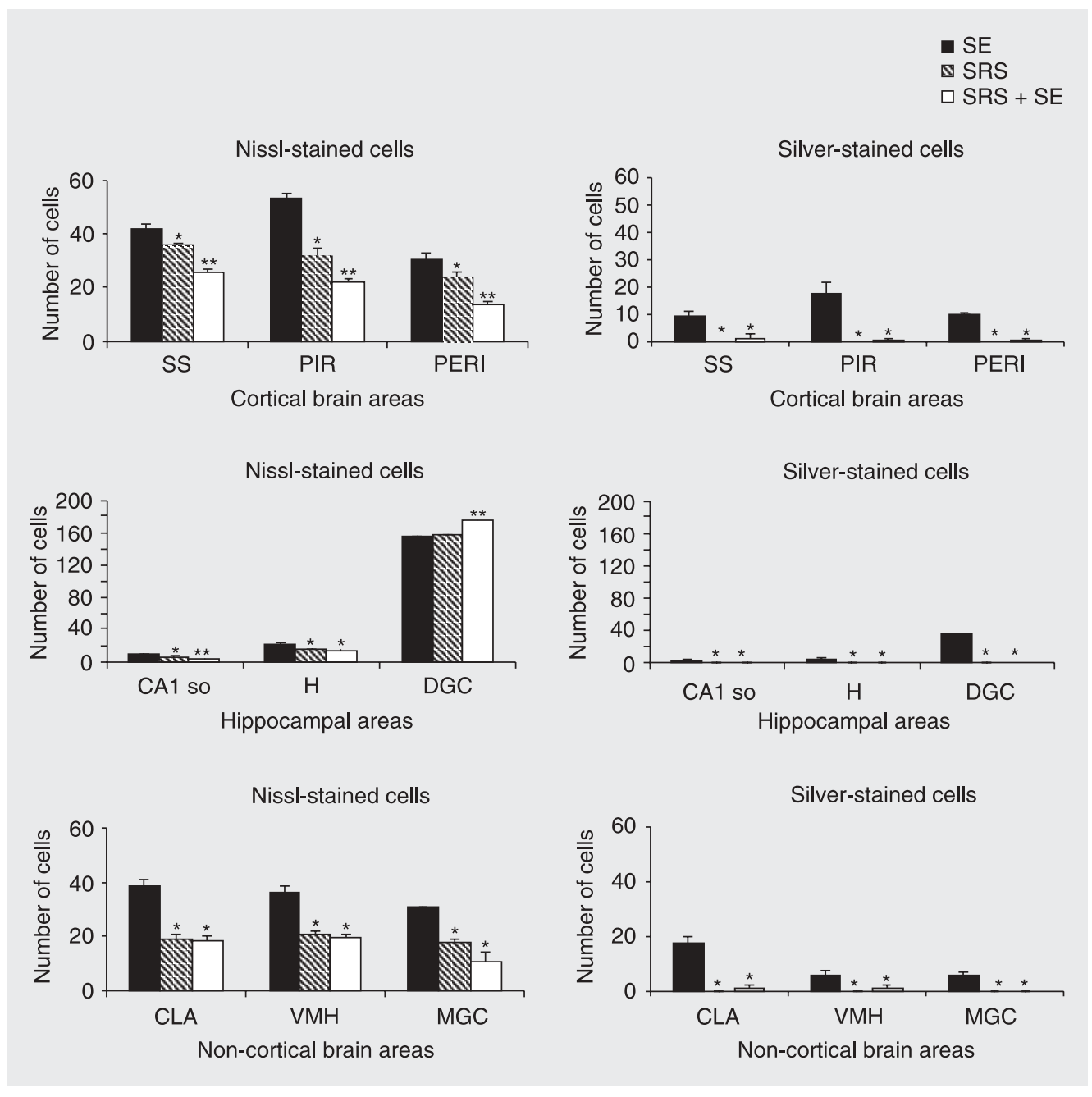

Figure 3. Cell counts of Nissland silver-stained sections for selected brain areas of the different experimental groups. Since cell counts were performed for the same areas in the same animals, Nissl-stained cells constitute all of the available cells for that animal group whereas silver-stained neurons should represent the lesioned fraction of the Nissl counts. Data are reported as means \pm SEM for 9 animals for the acute status epilepticus (SE) group, 21 animals for the chronic spontaneous recurrent seizures (SRS) group, and 6 animals for the second $\mathrm{SE}$ group. $\mathrm{SS}=$ somatosensory area; PIR = piriform cortex; $P E R I=$ perirhinal area; $C A 1$ so = hippocampal CA1 field, stratum oriens; $\mathrm{H}=$ hilus; $\mathrm{DGC}=$ dorsal geniculate complex; CLA = claustrum; $\mathrm{VMH}=$ ventromedial nucleus hypothalamus; MGC = medial geniculate complex. $* \mathrm{P}<0.01$ (ANOVA) and $\mathrm{P}$ $\leq 0.05$ (Scheffé post hoc test) relative to the SE group and **P $<0.01$ (ANOVA) and $P \leq 0.05$ (Scheffé post hoc test) relative to the SE and to the SRS groups. 
degenerate from 2 to $48 \mathrm{~h}$ after kainateinduced SE, also do not silver stain with the argyrophil III method after kainate-induced SE $(13,23)$. Similarly, there is intense silver staining of these same neurons from 2 to 48 $\mathrm{h}$ after pilocarpine-induced SE (current results and Ref. 24), a time-window in which this other epilepsy model is known to trigger degenerative processes in dentate granule cells (25).

The modest number of silver-stained cells after SRS reported here and the severe glial scar displayed by the older chronic animals suggest that much of the cell loss does not occur directly in association with SRS, but is more likely to be a protracted consequence of the initial SE (26). For animals sacrificed earlier (around 30 days) after SE induction, the occurrence of SRS was not sufficient to promote evident silver staining of neurons. Accordingly, recent data demonstrated the presence of Fluoro-Jade B-positive neurons approximately 60 days after SE, which did not correlate with the frequency of SRS in this time interval (21). Thus, the current observations and the available data suggest that the initial SE leads to both an initial major loss of neuronal cells and to a protracted less pronounced cell loss period that might extend for at least a few months.

An additional conclusion is that the neurons of these animals might have gained some sort of resistance to further damage (second SE) influenced by the previous history of seizures and neural activity, being thus resistant to damage by SRS. A detailed analysis of our data indeed suggests that, if present, the induced tolerance to further damage is not evenly distributed in the different brain areas. For hippocampal pyramidal cells this concept of an initial intense event killing some cells and yet conferring relative resistance to neighboring cells of the same type seems to be valid. Indeed, our findings about damage in the pyramidal cell layer indicate that the progression seems to be minimal even over a period of many months in some animals. Thus, for this case the first pilocarpine-induced SE generated substantial cell loss, regardless of the intensity and frequency of subsequent injuring events (SRS or SRS + $\mathrm{SE})$. It could be argued that the hippocampal pyramidal cells remaining after the first SE were already resistant to damage and that all of the vulnerable pyramidal cells were destroyed by the first SE. This, however, is not supported by the variable extension of cell damage among animals in this model of SE $(25,27)$. The same explanation (induced tolerance) might also apply to the somatosensory, piriform and perirhinal cortices, where the vulnerable population of cells was killed by the first $\mathrm{SE}$ and the remaining cells were not susceptible to the second one, which thus could also be seen as indicative of induced tolerance to damage.

Evidence for resistance to damage conferred by previous epileptic activity has been shown in a number of experiments by different groups $(10,28,29)$. However, in all of these studies assessment of the effects of a second lesional event was always performed within a short time interval after the first insult. Indeed, it was recently described that preconditioning animals by intrahippocampal kainic acid administration produces significant neuroprotection against a second intrahippocampal kainic acid dose administered from 1 to 7 days but not 15 days after injection (30). In addition, it has been long known that the induction of c-Fos expression by seizures, for example, has a refractory period of $18 \mathrm{~h}$ (31). Thus, it is not surprising for the above reports to have described neuroprotection or lack of lesion after a second lesional event. Here, however, a period of many months had passed between the initial major lesional event and the induction of the second SE. Under these conditions, the lack of an extensive lesion after the second SE was neither due to a lower degree of the second insult compared to the first nor to some sort of short-term refractoriness. Accordingly, our data could 
be seen as indicative of some sort of neuroprotection or excitotoxic-induced tolerance. The argument of a lack of vulnerable cells to be damaged by the second SE is not supported by our counts of the number of silverstained cells relative to the number of available neurons (Nissl stained).

We have previously reported that all dentate granule cells are not the same, and that cells at different septotemporal levels are differently vulnerable to SE-induced damage (32). Accordingly, this could be seen as favoring the hypothesis that the initial SE damaged all or most of the vulnerable cells in the dentate gyrus, with the second lesional event striking a subpopulation of rather resistant cells. However, also for the dentate gyrus our current data do not favor this hypothesis. The complete atrophy of the suprapyramidal dentate granule cell layer seen for one rat 15 months after SE induction suggests that, given enough time and insults (157 recorded SRS for this animal), even very resistant neuronal populations will show damage. In any event it seems logical to assume that neuronal populations will not be homogeneously vulnerable and that the "weaker" cells will be the first to be damaged. However, for this cell population, it must also be taken into consideration that, based on the current data and the high neuro- genesis rate after SE in this model of epilepsy (32), the number of dentate granule cells after the second SE is not necessarily indicative of resistance to further damage. Nevertheless, the absence of any silverstained dentate granule cells after the second SE suggests a tolerance effect provoked by the first SE. In conclusion, our data suggest that in some neuronal populations there is a tolerance to damage that is induced by pilocarpine SE and may extend for over 15 months after the initial insult. In addition, this "tolerance" to further damage does not seem to increase or diminish as a consequence of repeated SRS, irrespective of the frequency of these latter seizure events.

Finally, the protection conferred by the initial SE event is able to partially withstand even a second SE bout 6 months later. Our findings may be relevant to the interpretation of clinical studies trying to address whether neuronal damage is a cause or a consequence of seizures. Knowledge of the factors influencing such tolerance might be relevant to the development of neuroprotective strategies.

\section{Acknowledgments}

We wish to thank Ivone de Paulo for excellent technical assistance.

\section{References}

1. Arida RM, Scorza FA, Peres CA, Cavalheiro EA. The course of untreated seizures in the pilocarpine model of epilepsy. Epilepsy Res 1999; 34: 99-107.

2. Leite JP, Bortolotto ZA, Cavalheiro EA. Spontaneous recurrent seizures in rats: an experimental model of partial epilepsy. Neurosci Biobehav Rev 1990; 14: 511-517.

3. Mello LE, Cavalheiro EA, Tan AM, Kupfer WR, Pretorius J K, Babb $T L$, et al. Circuit mechanisms of seizures in the pilocarpine model of chronic epilepsy: cell loss and mossy fiber sprouting. Epilepsia 1993; 34: 985-995.

4. Lemos T, Cavalheiro EA. Suppression of pilocarpine-induced status epilepticus and the late development of epilepsy in rats. Exp Brain Res 1995; 102: 423-428.

5. Cendes F, Andermann F, Gloor P, Lopes-Cendes I, Andermann E,
Melanson D, et al. Atrophy of mesial structures in patients with temporal lobe epilepsy: cause or consequence of repeated seizures? Ann Neurol 1993; 34: 795-801.

6. Cavazos JE, Das I, Sutula TP. Neuronal loss induced in limbic pathways by kindling: evidence for induction of hippocampal sclerosis by repeated brief seizures. J Neurosci 1994; 14: 3106-3121.

7. Sutula TP, Pitkanen A. More evidence for seizure-induced neuron loss: is hippocampal sclerosis both cause and effect of epilepsy? Neurology 2001; 57: 169-170.

8. McIntyre DC, Kelly ME. Are differences in dorsal hippocampal kindling related to amygdala-piriform area excitability? Epilepsy Res 1993: 14: 49-61.

9. Mello LE, Tan AM, Finch DM, Kohman CM, Cavalheiro EA. Fos-like immunoreactivity after status epilepticus and spontaneous seizures 
in rats. Epilepsy Res Suppl 1996; 12: 205-213.

10. Najm IM, Hadam J , Ckakraverty D, Mikuni N, Penrod C, Sopa C, et al. A short episode of seizure activity protects from status epilepticus-induced neuronal damage in rat brain. Brain Res 1998; 810: 7275.

11. Sasahira M, Lowry T, Simon RP, Greenberg DA. Epileptic tolerance: prior seizures protect against seizure-induced neuronal injury. Neurosci Lett 1995; 185: 95-98.

12. Toth Z, Hollrigel GS, Gorcs T, Soltesz I. Instantaneous perturbation of dentate interneuronal networks by a pressure wave-transient delivered to the neocortex. J Neurosci 1997; 17: 8106-8117.

13. Covolan L, Mello LE. Temporal profile of neuronal injury following pilocarpine or kainic acid-induced status epilepticus. Epilepsy Res 2000; 39: 133-152.

14. Ishida K, Shimizu H, Hida H, Urakawa S, Ida K, Nishino H. Argyrophilic dark neurons represent various states of neuronal damage in brain insults: some come to die and others survive. Neuroscience 2004; 125: 633-644.

15. van den Pol AN, Gallyas F. Trauma-induced Golgi-like staining of neurons: a new approach to neuronal organization and response to injury. J Comp Neurol 1990; 296: 654-673.

16. Gallyas F, Hsu M, Buzsaki G. Four modified silver methods for thick sections of formaldehyde-fixed mammalian central nervous tissue: 'dark' neurons, perikarya of all neurons, microglial cells and capillaries. J Neurosci Methods 1993; 50: 159-164.

17. Horváth Z, Hsu M, Pierre E, Vadi D, Gallyas F, Buzsaki G. Structural impairment in hippocampal neurons following a single epileptic afterdischarge. Epilepsy Res 1996; 12 (Suppl): 325-334.

18. Swanson LW. Brain maps: structure of the rat brain. Amsterdam: Elsevier; 1992.

19. Mello LE, Covolan L. Spontaneous seizures preferentially injure interneurons in the pilocarpine model of chronic spontaneous seizures. Epilepsy Res 1996; 26: 123-129.

20. Turski WA, Cavalheiro EA, Schwarz M, Czuczwar SJ, Kleinrok Z, Turski L. Limbic seizures produced by pilocarpine in rats: behavioural, electroencephalographic and neuropathological study. Behav Brain Res 1983; 9: 315-335.

21. Pitkanen A, Nissinen J, Nairismagi J, Lukasiuk K, Grohn OH, Miettinen $R$, et al. Progression of neuronal damage after status epilepticus and during spontaneous seizures in a rat model of tem- poral lobe epilepsy. Prog Brain Res 2002; 135: 67-83.

22. Dube C, Andre V, Covolan L, Ferrandon A, Marescaux C, Nehlig A. C-Fos, J un D and HSP72 immunoreactivity, and neuronal injury following lithium-pilocarpine induced status epilepticus in immature and adult rats. Brain Res Mol Brain Res 1998; 63: 139-154.

23. Pollard $\mathrm{H}, \mathrm{Charriaut-Marlangue} \mathrm{C}$, Cantagrel $\mathrm{S}$, Represa A, Robain 0 , Moreau J, et al. Kainate-induced apoptotic cell death in hippocampal neurons. Neuroscience 1994; 63: 7-18.

24. Covolan L, Smith RL, Mello LE. Ultrastructural identification of dentate granule cell death from pilocarpine-induced seizures. Epilepsy Res 2000; 41: 9-21.

25. Fujikawa DG. The temporal evolution of neuronal damage from pilocarpine-induced status epilepticus. Brain Res 1996; 725: 11-22.

26. Gorter J A, Goncalves Pereira PM, van Vliet EA, Aronica E, Lopes da Silva FH, Lucassen PJ. Neuronal cell death in a rat model for mesial temporal lobe epilepsy is induced by the initial status epilepticus and not by later repeated spontaneous seizures. Epilepsia 2003; 44: 647-658.

27. Poirier J L, Capek R, De Koninck Y. Differential progression of Dark Neuron and Fluoro-J ade labelling in the rat hippocampus following pilocarpine-induced status epilepticus. Neuroscience 2000; 97: 5968.

28. Kelly ME, McIntyre DC. Hippocampal kindling protects several structures from the neuronal damage resulting from kainic acid-induced status epilepticus. Brain Res 1994; 634: 245-256.

29. Zhang X, Cui SS, Wallace AE, Hannesson DK, Schmued LC, Saucier DM, et al. Relations between brain pathology and temporal lobe epilepsy. J Neurosci 2002; 22: 6052-6061.

30. El Bahh B, Lurton D, Sundstrom LE, Rougier A. Induction of tolerance and mossy fibre neuropeptide-Y expression in the contralateral hippocampus following a unilateral intrahippocampal kainic acid injection in the rat. Neurosci Lett 1997; 227: 135-139.

31. Morgan JI, Cohen DR, Hempstead J L, Curran T. Mapping patterns of c-fos expression in the central nervous system after seizure. Science 1987; 237: 192-197.

32. Covolan L, Ribeiro LT, Longo BM, Mello LE. Cell damage and neurogenesis in the dentate granule cell layer of adult rats after pilocarpine- or kainate-induced status epilepticus. Hippocampus 2000; 10: 169-180. 